\title{
Isolation of bacteria from normal external auditory canal
}

\author{
Prasanna $\mathrm{V}^{1}$, Edwin $\mathrm{B}^{2}$ and Kannan $\mathrm{I}^{3}$ \\ ${ }^{1}$ Dr Vincent Prasanna, Professor, Department of ENT, Tagore Medical College and Hospital, Chennai, ${ }^{2}$ Dr Beulah \\ Edwin, Associate Professor, Department of Microbiology, Tagore Medical College and Hospital, Chennai, India, ${ }^{3} \mathrm{Dr}$ \\ Kannan I, Associate Professor, Department of Microbiology, Tagore Medical College and Hospital, Chennai, India.
}

Address for Correspondence: Dr. Vincent Prasanna, Professor and Head, Department of ENT, Tagore Medical College and Hospital, Rathinamangalam, Chennai, India, E. mail: vincent.prasanna@gmail.com.

\begin{abstract}
Introduction: Otits Externa is one of the commonest condition with which patients attend the ENT clinics throughout the world. Like the skin, the external auditory canal has the possibility of harboring normal bacterial flora. There is no proper literature regarding the normal bacterial flora of external auditory canal. Thus the clinicians are posed with the difficulty in interpreting the laboratory diagnostic report. Aim of the Study: The aim of the present study is to assess the aerobic bacterial flora of the healthy human ear canal. Materials and Methods: 100 individuals were selected for the study. The sample was collected in the form of ear swabs. The swabs were subjected to culture initially in BHI broth followed by Blood agar and MacConkey agar. The organisms grown were identified by standard biochemical reactions. Results: The present study showed that the S. epidermidis is the commonest bacteria isolated (94\%) followed by other bacteria viz., S. aureus, E. coli, P. aeroginosa and diphtheroids. Conclusion: The present study concludes that certain pathogenic bacteria which can cause otitis externa are present as normal commensals in the external auditory canal. Hence the clinicians should elicit the history of any predisposing factors before interpreting laboratory culture reports.
\end{abstract}

Keywords: Otitis Externa, Normal Bacterial Flora, External Auditory Canal.

\section{Introduction}

The infection or inflammation of the external auditory canal is normally referred to as Otitis externa. The disease as such may be mild inflammation or can even present as osteomyelitis of the base of the skull. It is the commonest condition with which patients attend the ENT clinics throughout the world [1].

Like the skin, the external auditory canal has the possibility of harbouring normal bacterial flora [2]. The bacterium which is predominantly isolated is Staphylococcus aureus [3,4]. Many studies were done to find possible microorganisms involved in otitis externa [5-7]. The aetiology of most of the otitis externa is considered to be bacterial and fungal origin [8-11]. Further all the studies showed a polymicrobial nature of otitis externa. This raises a question whether all these microbes are involved in the otitis externa or only one organism is involved in the disease and remaining are normal commensals present in the external auditory

Manuscript received: $24^{\text {th }}$ June 2015

Reviewed: $4^{\text {th }}$ July 2015

Author Corrected: $14^{\text {th }}$ July 2015

Accepted for Publication: $18^{\text {th }}$ July 2015 canal. Factors that may predispose to acute otitis externa include a congenitally narrow canal or a canal narrowed by exostoses; skin conditions that include eczema, seborrhea or psoriasis; or trauma from ear plugs, hearing aids, or wax removal attempts [12]. Climatic conditions such as hot and humid weather and swimming can also predispose for Otitis externa.

There is no proper literature regarding the normal bacterial flora of external auditory canal. Thus the clinicians are posed with the difficulty in interpreting the laboratory diagnostic report.

Knowledge of the bacterial flora of the human ear canal in health is essential in evaluating the possible etiologic significance of organisms cultured from the diseased canal. Hence the aim of the present study is to assess the aerobic bacterial flora of the healthy human ear canal.

\section{Materials and Methods}


The study design was prospective cross sectional observational study. A total of 100 participants were included in this study. The inclusion criteria is presence of a normal external auditory canal. The exclusion criteria were discharging ear, $\mathrm{H} / \mathrm{O}$ of prior ear discharge, ear pain and recent use of antiobiotics, either oral or topical.

An external ear canal swab was taken and transported immediately to the laboratory. The swab was incubated in BHI broth at $37^{\circ} \mathrm{C}$ for two hours for the recovery of bacteria. It was then inoculated on Blood agar and
MacConkey agar and incubated overnight at $37^{\circ} \mathrm{C}$ for 48 hours.

After 24 hours, the plates were observed for growth if any and incubated further if no growth occurred. Once growth occurred on plates, the colony morphology was noted and a smear of the colony was prepared and gram stained. If more than one morphological type was found, a smear of each type of colony was prepared and gram stained and the morphology of the bacteria noted. Individual colonies were picked up for further speciation and identification was done by the standard biochemical reactions.

\section{Results}

Swabs were taken from the external ear canal of hundred healthy individuals. Among which 7 individuals did not show the presence of any bacteria. All the remaining individuals showed the presence one or many bacteria. The incidence of the organisms making up the flora of the human external auditory canal in health is shown in Table 1.

\section{Table 1: Bacteria isolated from external auditory canal}

\begin{tabular}{|l|l|l|}
\hline Name of the bacteria & Number of patients & Percentage \\
\hline Staphylococcus aureus & 23 & 24.7 \\
\hline Staphylococcus epidermidis & 88 & 94.6 \\
\hline Diphtheroids & 7 & 7.5 \\
\hline Escherichia coli & 5 & 5.4 \\
\hline Pseudomonas aeroginosa & 3 & 3.2 \\
\hline
\end{tabular}

From the table it is evident that the S. epidermidis is the commonest bacteria isolated (94\%) followed by other bacteria viz., S. aureus, E. coli, P. aeroginosa and diphtheroids.

\section{Discussion}

Otitis externa is a common problem encountered in daily clinical practice by ENT surgeon as well as general practitioners. It can present as a simple, easily treatable illness in an immunocompetent individual to a severe life-threatening infection in the immunocompromised. Acute otitis externa is a common problem in swimmers. Swimming in contaminated water (lakes and rivers) increases the risk of pseudomonas otitis externa [13].

The increase in moisture in the external auditory canal causes edema and a more favorable environment for bacterial overgrowth. Cerumen has an acidic $\mathrm{pH}$, and helps prevent bacterial growth in the EAC. A lack of cerumen and exposure to moisture predisposes to infection. Cleaning with cotton applicators can traumatize the thin epithelial lining of the bony EAC, which then predisposes to infection. Patients who wear hearing aids also are at increased risk of otitis externa because of the moist environment that is created in the ear canal and because of occasional EAC trauma. All of the above factors can create an environment that is optimal for bacterial growth, particularly pseudomonas and to a lesser degree staphylococcal species [14].

In the immunocompromised such as in poorly controlled diabetic patients, otitis externa can present as a severe and aggressive infection. It is termed as Necrotizing otitis externa. Also known as "Malignant Otitis Externa," the disease can involve the temporal bone and skull base, and is essentially an osteomyelitis of the skull base (Skull base Osteomyelitis). It is usually caused by Pseudomonas sp. If not aggressively treated it can result in several intratemporal, intracranial complications and can also turn out to be fatal [15].

The aim of the present study is to find the possible bacteria in the normal external auditory canal. Only five types of bacteria were isolated in the present study. The 
various studies conducted to find the bacteria involved in otitis externa showed the predominant bacteria isolated was Staphylococcus aureus followed by Pseudomonas aeroginosa [15, 16]. In our study, Staphylococcus epidermidis $(94.6 \%)$ was the most common organism isolated followed by Staphylococcus aureus (24.7\%), Diphtheroids (7.5\%), Escherichia coli $(5.4 \%)$ and Pseudomonas aeroginosa (3.2\%). Our results were similar to the Norwegian study where they isolated Staphylococcus epidermidis (83\%) followed by Diphtheroids (32\%) and Staphylococcus aureus (7\%) [17]

In the present study Staphylococcus aureus and Pseudomonas aeroginosa were isolated from normal external auditory canal which are common isolates in otitis externa. Other studies have also yielded similar results [18]. The commensal Staphylococcus aureus which was isolated frequently in present study can cause localized otitis externa i.e furunculosis whenever there is a predisposing factors like trauma. Further Pseudomonas aeroginosa seen normal external auditory ear canal can cause otitis externa in certain predisposed individuals.

Thus when interpreting the results of ear swabs in patients with various forms of otitis externa, we should take into consideration the various predisposing factors like ear trauma, frequent exposure to water, persistent ear discharge, seborrhea in addition to the microbial culture results. In order to arrive at a clinical diagnosis, it is imperative that the clinician should take into consideration, the culture report, the predisposing factors and the clinical picture before initiating treatment.

\section{Conclusion}

The present study concludes that certain pathogenic bacteria which can cause otitis externa are present as normal commensal in the normal external auditory canal. Hence the clinicians should find the history of any predisposing factors before interpreting laboratory culture reports.

\section{Funding: Nil}

Conflict of interest: Nil

Permission from IRB: Yes
1. Halpern MT, Palmer CS, Seidlin M. Treatment patterns for otitis externa. J Am Board Fam Pract 1999 Jan-Feb; 12(1):1-7.

2. Bojrab DI, Bruderly T, Abdulrazzak Y. Otitis externa.Otolaryngol Clin North Am 1996 Oct ; 29(5):761-82.

3. Clark WB, Brook I, Bianki D, Thompson DH. Microbiology of otitis externa. Otolaryngol Head Neck Surg. 1997 Jan;116(1) :23-5

4. Dibb WL. Microbial aetiology of otitis externa. J Infect. 1991 May;22(3):233-9.

5. Amigot SL, Gomez CR, Luque AG, Ebner G. Microbiological study of external otitis in Rosario City [Ms1], Argentina. Mycoses. 2003 Sep;46 (8) :312-5

6. Loh KS, Tan KK, Kumarasinghe G, Leong HK, Yeoh KH. Otitis externa - the clinical pattern in a tertiary institution in Singapore. Ann Acad Med Singapore. 1998 Mar;27(2):215-8.

7. Zaror L, Fischman O, Suzuki FA, Felipe RG. Otomycosis in Sao Paulo. Rev Inst Med Trop Sao Paulo 1991May - Jun;33(3):169-73.

8. Boustred N. Practical guide to otitis externa. Aust Fam Physician.1999 Mar;28(3):217-21.

9. Martin TJ, Kerschner JE, Flanary VA. Fungal causes of otitis externa and tympanostomy tube otorrhea. Int $\mathbf{J}$ Pediatr Otorhinolaryngol. 2005 Nov;69(11):1503-8.

10. Pino Rivero V, Pantoja Hernandez CG, Gonzalez Palomino G, Mora Santos ME, Pardo Romero G, Blasco Huelva A. Pseudomonas and acute external otitis. Results of a microbiological study in patients without previous antibiotic treatment. An Otorrinolaringol Ibero Am. 2007;34(1):45-51

11. Jadhav VJ, Pal M, Mishra GS. Etiological significance of Candida albicans in otitis externa. Mycopathologia. 2003;156(4):313-5.

12. Rosenfeld RM, Brown L, Cannon CR, et al: Clinical practice guideline:acute otitis externa. Otolaryngol Head Neck Surg. 2006 Apr;134(4 Suppl):S4-23.

13. Hajjartabar M. Poor-quality water in swimming pools associated with a substantial risk of otitis externa 
due to Pseudomonas aeruginosa. Water Sci Technol 2004;50(1):63-67.

14. Roland PS, Stroman DW. Microbiology of acute otitis externa. Laryngoscope 2002 Jul ;112(7 pt 1):1166-1177.

15. Agius AM, Pickles JM, Burch KL. A prospective study of otitis externa. Clin Otolaryngol Allied Sci. 1992 Apr;17(2):150-154.

16. Cassisi N, Cohn A, Davidson T,Witten BR. Diffuse otitis externa: clinical and microbiologic findings in the course of a multicenter study on a new otic solution. Ann Otol Rhinol Laryngol Suppl. 1977 May -Jun;86(3 Pt 3 Suppl 39):1-16.

17. Dibb WL.The normal microbial flora of the outer ear canal in healthy Norwegian individuals.NIPH Ann.1990 Jun;13(1): 11-6.

18. Stroman DW, Roland PS, Dohar J, Burt W. Microbiology of normal external auditory canal. Laryngoscope. 2001 Nov;111(11 Pt 1):2054-9.

\section{How to cite this article?}

Prasanna V, Edwin B, Kannan I. Isolation of bacteria from normal external auditory canal. Int J Med Res Rev 2015;3(6):597-600. doi: 10.17511/ijmrr.2015.i6.116. 